\title{
A trajetória do filme-revista no Brasil: um estudo de Caídos do céu (1946)
}

Evandro Gianasi Vasconcellos, Universidade Federal de São Carlos, São Carlos, SP; E-mail: <evandrogianasi@gmail.com>.

\section{Resumo}

Este trabalho tem como objetivo discutir a existência de um filão cinematográfico que se relaciona diretamente com aspectos do teatro de revista, um tipo de espetáculo com elementos e convenções bem definidos e de grande sucesso no Brasil entre - final do século XIX e primeira metade do século XX, principalmente. Através de uma revisão da produção cinematográfica brasileira, pretendemos demonstrar a existência de uma trajetória de filmes-revista no Brasil, que compreende filmes realizados na primeira década do século passado, na chamada "Bela Época", com destaque para o grande sucesso de Paz e amor (Alberto Moreira, 1910), até as comédias carnavalescas dos anos 1930 e 1940. A partir disso, em um estudo de caso do filme Caídos do céu (Luiz de Barros, 1946), anunciado nos jornais como uma revista carnavalesca e dirigido por Luiz de Barros, cineasta que também trabalhou muitos anos com teatro de revista, procuraremos identificar alguns pontos de contato entre os dois meios artísticos, observando aspectos como números musicais, elenco, enredo, entre outros.

Palavras-chave: cinema brasileiro, teatro de revista, filme-revista, Luiz de Barros, Caídos do céu, gêneros cinematográficos.

Este trabalho surgiu de um projeto de mestrado em andamento, que se propõe a estudar as relações entre o teatro de revista e as comédias carnavalescas, a partir da análise de dois filmes de longa-metragem realizados por Luiz de Barros na produtora carioca Cinédia nos anos 1940: Berlim na batucada (1944) e Caídos do céu (1946). Nesses filmes é possível perceber um forte diálogo com um tipo de entretenimento de bastante sucesso de público nos teatros do Rio de Janeiro.

O teatro de revista enquanto gênero sofreu grandes alterações desde o final do século XIX, momento em que se popularizou no país com as "revistas de ano", até o decorrer, 
principalmente, da primeira metade do século XX. Nesse período podemos encontrar diversos filmes que se relacionam com o gênero teatral em alguma medida, sendo inclusive divulgados como "revistas" em suas publicidades. Deste modo, buscamos aqui esboçar uma rápida "trajetória" do filme-revista no Brasil para então nos determos em uma análise do filme Caídos do céu, com o propósito de refletir sobre quais características do filme nos levam a traçar essas relações com o teatro de revista.

A escolha por um filme de Luiz de Barros não é aleatória. Embora seja reconhecido principalmente como cineasta, contando com dezenas de filmes em sua longa carreira de mais de sessenta anos, Barros também trabalhou com teatro de revista, cassinos, prólogos cinematográficos, entre outras formas artísticas. Ainda na década de 1920, Luiz de Barros foi cenógrafo, figurinista, diretor artístico e também montou companhias de teatro de revista, sendo a Companhia Ra-taplan a mais comentada em trabalhos da área. Com isso, o diretor possuía larga experiência também no meio teatral.

Durante as décadas de 1930 e 1940 a Cinédia realizou um considerável número de filmes, sendo uma das principais produtoras do país naquele momento. Boa parte dessa filmografia era composta por obras que possuíam características populares e se utilizavam de elementos da cultura de massa, como a música e o carnaval. Nesses filmes o diálogo com outros meios artísticos de grande apelo popular, como o rádio e o teatro de revista, é uma das formas encontradas para atrair um público mais amplo. Luiz de Barros dirigiu para a Cinédia diversas comédias musicais, geralmente realizadas com poucos recursos e com lançamentos vinculados ao período carnavalesco. O elenco com artistas conhecidos do teatro de revista e a presença de vários cantores interpretando sambas e marchinhas de carnaval era frequente nesse tipo de produção. Os números musicais pouco se relacionam com o 
enredo do filme, formando geralmente uma narrativa fragmentada que se assemelha às revistas teatrais ${ }^{1}$.

\section{O filão "filme-revista"}

No livro Historiografia clássica do cinema brasileiro (1995), Jean-Claude Bernardet faz uma importante discussão metodológica, onde rejeita a ideia de uma história dividida em ciclos para se pensar o cinema brasileiro ${ }^{2}$ e sugere:

Não deveríamos rechaçar o corte cronológico vertical, e
trabalhar horizontalmente com filões que apresentariam
ritmos diferenciados e tentar estabelecer entre eles
relações, sem querer encaixá-los em unidades temporais
consideradas válidas para todos os filões? (Bernardet,
1995: 59). O que propomos aqui é pensar em uma "linha de coerência", esboçando uma trajetória em que filmes realizados em momentos distintos, como Paz e amor (Alberto Moreira, 1910), produção da chamada "Bela época", e Caídos do céu (Luiz de Barros, 1946), sejam reconhecidos como pertencentes a um mesmo filão cinematográfico, tendo em comum o diálogo com aspectos do teatro de revista.

No final da primeira década do século $X X$, popularizaram-se no Rio de Janeiro os cantantes, filmes musicados que se caracterizavam por serem dublados durante a projeção por artistas atrás da tela. Grande parte desses filmes era composta de operetas. A viúva alegre (William Auler, 1909) foi um filme de grande repercussão no período, motivando a realização de várias versões da mesma opereta. Dentro desse período de

\footnotetext{
${ }^{1}$ Como referência principal para os elementos e convenções do teatro de revista, utilizamos o livro de Neyde Veneziano, O teatro de revista no Brasil: dramaturgia e convenções (1991).

2 Bernardet critica principalmente os estudos panorâmicos de Alex Viany e Paulo Emilio Salles Gomes, que chamará de historiografia clássica do cinema brasileiro (Bernardet, 1995: 13).
} 
produção dos cantantes, outro filão surge na cinematografia brasileira: o filme-revista.

A adaptação desse gênero de teatro popular para a tela do cinema causará grande repercussão com o lançamento de Paz e amor em 25 de abril de 1910, no cinema Rio Branco, no Rio de Janeiro. O filme dirigido por Alberto Moreira e com câmera de Alberto Botelho assume sua relação com o teatro de revista desde a publicidade, sendo anunciado como uma "revista de costumes e atualidade" (Gazeta de Notícias, 25 abr 1910: 8) ${ }^{3}$, até o formato, com cinco quadros e duas apoteoses. A temática de sátira política e crítica de costumes e os personagens caricaturais também são características herdadas do teatro.

No mesmo ano outras produções são lançadas, também se utilizando do sucesso do gênero nos palcos para atrair público para os cinemas. Vários filmes são anunciados como revistas, como: O cometa; O Chantecler, O Rio por um óculo; e 606.

Com a chegada definitiva do som ao cinema, na segunda metade dos anos 1920, ocorre um reaquecimento do gênero, facilitado pela possibilidade da música sincronizada. Nos primeiros anos do cinema sonoro proliferaram as revistas musicais hollywoodianas exibidas no país, como, por exemplo: Hollywood revue (The Hollywood revue of 1929, Charles Reisner, 1929); Follies (Fox Movietone Follies of 1929, David Butler, 1929), "revista teatral de 1929"; e Broadway scandals (George Archainbaud, 1929), um "super filme-revista". Esses filmes eram anunciados como revistas e se utilizavam da estrutura de quadros musicados, com cenários luxuosos e grandes elencos.

${ }^{3}$ Todas as matérias de jornais citadas no texto estão disponíveis na página da hemeroteca digital da Biblioteca Nacional:

http://hemerotecadigital.bn.br/ 
Rafael de Luna Freire afirma que "o gênero 'revista' permanecia claro e codificado no Brasil ao ponto de ser usado como uma das categorias genéricas nas classificações estatísticas de obras cinematográficas do IBGE ao longo da década de 1930" (Freire, 2011: 240).

Nos primeiros anos de cinema sonoro, a realização do filme paulista Coisas nossas (Wallace Downey, 1931) apresentará influências do musical americano e, sobretudo, do teatro de revista. Através da descrição de Fernando Morais da Costa (2006), feita a partir da audição de parte dos discos da faixa sonora do filme, único material existente do filme desaparecido, podemos perceber uma estrutura com vários números musicais e esquetes rápidas que não chegam a formar um enredo articulado. Essa composição fragmentada se assemelha aos filmes revistas americanos, mas também encontram parentesco no teatro brasileiro, por conta dos artistas envolvidos na produção e da temática dos quadros.

Em 1933 a Cinédia lança $A$ voz do carnaval (Adhemar Gonzaga e Humberto Mauro). A opção pelas comédias musicais visava uma maior aproximação com o público, apresentando músicos reconhecidos e artistas cômicos, muitos oriundos do teatro popular. A relação com o teatro de revista apareceria de maneira mais evidente no filme Alô, Alô, Carnaval (Adhemar Gonzaga \& Wallace Downey, 1936), como aponta Freire:

Como um autointitulado "filme-revista", o longa-
metragem narrava as desventuras de dois autores
pobretões (Barbosa Junior e Pinto Filho) para conseguir
montar a revista Banana da terra no luxuoso Cassino
Mosca Azul. Ou seja, descrevia em forma de comédia o
processo de levar a revista à cena. Mas paralelamente a
esse fio de história sobre os bastidores da montagem do
espetáculo, eram encenados desde o início do filme,
como uma revista filmada (e sob a influência do rádio e
do disco), diversos números de astros da música
brasileira nos palcos do tal cassino (Freire, 2011: 243 ,
grifo do original). O lançamento de comédias musicais no período carnavalesco se torna recorrente e diversos filmes serão produzidos com a 
presença de marchinhas de carnaval interpretadas por cantores conhecidos dos discos e do rádio, como por exemplo: Banana-da-terra (Rui Costa, 1939); Berlim na batucada (Luiz de Barros, 1944); e Tristezas não pagam dívidas (Ruy Costa e José Carlos Burle, 1944), entre outros. Luiz de Barros realizará para a Cinédia alguns filmes com essa característica, entre eles Caídos do céu (1946). Ao analisarmos o filme podemos perceber diversos aspectos em comum com o teatro de revista e outros tipos de entretenimento do período, demonstrando um diálogo interessante com o universo artístico da época.

\section{Caídos do céu: uma revista carnavalesca}

Caídos do céu foi o filme produzido para ser lançado no início de 1946, no chamado "carnaval da vitória", slogan dado pela Prefeitura do Rio de Janeiro para o primeiro carnaval após o fim da Segunda Guerra. Em seu cartaz ${ }^{4}$ o filme é anunciado como uma "revista carnavalesca do outro mundo", seguido de uma lista com os nomes dos atores e cantores presentes no filme.

Embora a intenção desse tipo de produção fosse chegar às salas de cinema antes do carnaval, problemas com um exibidor impossibilitaram que o filme fosse lançado na data prevista para o Rio de Janeiro. O produtor Adhemar Gonzaga conta em entrevista para um jornal da época que "certo exibidor não concordou com a divisão regulamentar dos cinquenta por cento sobre a renda. Perdura o impasse, com evidente prejuízo para o produtor" (A Noite, 27 fev 1946: 5).

Sendo assim, o filme é lançado primeiro em São Paulo, dia 25 de fevereiro, no cinema Art-Palácio, e posteriormente estreia no cinema São Carlos, na Cinelândia carioca, em abril do

\footnotetext{
${ }^{4}$ Cartaz disponível no site da Cinédia:

http://www.cinedia.com.br/Cartaz3.html
} 
mesmo ano. Os jornais do Rio de Janeiro anunciam o filme agora como "uma comédia musical do outro mundo", devido ao lançamento tardio, tendo já passado o carnaval. Ainda assim, Caídos do céu permanece quatro semanas nessa mesma sala, o que demonstra o interesse do público nesse tipo de produção.

A parte musical é sustentada por números com: Trio de Ouro, composto por Dalva de Oliveira, Herivelto Martins e Nilo Chagas; Francisco Alves; Linda Batista; Isaurinha Garcia; Ataulfo Alves e suas pastoras, entre outros, cantando músicas do carnaval daquele ano e algumas canções do ano anterior.

No teatro de revista a ligação com o carnaval se consolidará a partir dos anos 1910, quando "as músicas e as alusões aos principais blocos carnavalescos estimulavam a participação da plateia, proporcionando acirradas competições entre as torcidas nos teatros" (Antunes, 2002: 34). Na chamada "revista carnavalesca", tipo de espetáculo feito para o início do ano, o palco funcionava como um divulgador das músicas que estariam na boca dos foliões durante os dias da festa. Assim, é compreensível o fato do filme utilizar a mesma alcunha, uma vez que um dos grandes atrativos eram os números musicais.

O filme apresenta um enredo cômico bastante comum no teatro popular, centrado na figura dos personagens Rita Naftalina (Dercy Gonçalves) e Claudionor (Walter D'Avila), anjos que viveram no século XVIII. Sob o pretexto de buscarem informações sobre o recém-falecido Felizardo Boaventura (Augusto Aníbal), os dois irão conhecer diversos locais de entretenimento cariocas, tais como: estádio de futebol; teatro; cassino; dancing; cinema; e, claro, o carnaval. Na maioria desses lugares eles presenciam números musicais, "passando em revista" o roteiro de diversões da capital federal. A dupla faz ainda papel de cupido, ajudando na união de um casal (Átila lório e Nelma Costa), e até vão para a cadeia por não pagarem um taxista. Deste modo, cada cena funciona mais ou menos como um quadro independente, embora a narrativa linear 
encontre sua resolução no momento em que os anjos descobrem o sobrinho do falecido, que atesta seu caráter e seu direito a um lugar no céu.

Os protagonistas celestes, interpretados pelos conhecidos Walter d'Avila e Dercy Gonçalves, funcionam como os antigos compères e comères das revistas, acompanhando toda a narrativa e comentando os quadros musicais. Sobre a função do compère, Neyde Veneziano esclarece que era um:

Aglutinador, apresentador, comentarista, dançarino,
cantor, bufão, contador de piadas, ele atravessa a revista
ponta a ponta como a costurar os diversos quadros,
cristalizando a dinâmica do pacto com a plateia,
característica própria do teatro popular. Este papel era
geralmente reservado ao primeiro cômico da companhia,
que o deveria desempenhar com brilho, desenvoltura e,
principalmente, com muita descontração, pois muitas
vezes se fazia necessário o improviso com relação ao
comportamento do público (Veneziano, 1991: 117). Naquele momento os dois artistas já tinham uma carreira consolidada no teatro de revista como artistas cômicos, atuando como estrelas das companhias em que trabalhavam. Mas quem se destaca no filme é Dercy, que consegue conduzir com grande habilidade, muitas vezes na base do improviso, várias cenas.

Outros artistas oriundos do teatro também fazem parte do elenco, como: Augusto Aníbal, figura conhecida dos palcos, que também já havia feito alguns filmes, inclusive de Luiz de Barros; César Fronzi e Violeta Ferraz, que interpretam os pais da jovem defendida pelos anjos; Pedro Dias, como um guarda que prende os anjos; entre outros.

Chocolate, nome artístico de Dorival Silva, interpreta um malandro que acompanha os protagonistas em diversas cenas. $\mathrm{O}$ artista fez alguns filmes na Cinédia, mas ficaria mais conhecido depois, trabalhando como humorista no rádio e na televisão.

Nem só do teatro de revista as comédias retiravam suas referências, mas sim de diversos meios da cultura popular. A 
presença de Adoniran Barbosa no filme mostra o diálogo com o rádio não só através da música, mas também pelo humor radiofônico. Cabe ressaltar a importância do rádio como meio de comunicação e entretenimento naquele momento, anterior à chegada da televisão. Adoniran interpreta no filme o vendedor e alfaiate judeu Moisés Rabinovitch, personagem criado em um programa de humor da rádio Record de São Paulo, onde o artista trabalhava. Este mesmo personagem também aparecia em shows ao vivo que o ator fazia em teatros. No filme Adoniran Barbosa também interpreta a canção "Cortando o pano" (Luiz Gonzaga, Miguel Lima, J. Portela), lançada por Luiz Gonzaga no ano anterior.

No rádio Adoniran era dirigido por Oswaldo Moles, também creditado como autor dos diálogos de Caídos do céu. Tanto Adoniran quanto a cantora Isaurinha Garcia aparecem nos créditos como artistas da rádio Record, que também é citada no filme, quando o rapaz Roberto Boaventura (Átila lório) assina um contrato com a emissora e ganha a aprovação do futuro sogro.

Em relação aos números musicais, a ligação com o teatro de revista é marcante, principalmente na cena em que os anjos vão a um teatro. No palco está uma escola de samba comandada por Herivelto Martins, artista de grande importância na música popular, com a música "Fala, Claudionor" (Herivelto Martins e Grande Otelo), seguido de Francisco Alves, estrela radiofônica e do teatro de revista, interpretando o recente samba "Vaidosa", composição do próprio Herivelto Martins com Artur Morais. Os números fazem referência às revistas carnavalescas, que chegavam a levar escolas de samba completas para os palcos.

Em geral os números musicais são filmados em plano aberto frontal, como se víssemos de uma plateia de teatro, o que também acelerava as filmagens devido a economia de planos. Como exemplo os quadros com Linda Batista, Marlene e As pequenas do barulho. 
Na música "Momo Boogie" (Denis Brean), com Linda Batista, há um navio cenográfico atracado de fundo, além da presença de várias dançarinas, em um dos números musicais mais elaborados do filme, uma vez que grande parte deles são bem precários, tendo poucos elementos como cenário.

Outro momento musical interessante se passa em um cassino, no quadro "O balanceio". O número musical do filmado em plano aberto frontal, salvo por alguns poucos planos mais próximos, enquadrando o palco inteiro de cima, de modo a mostrar o desenho dos dançarinos no palco. O quadro em questão aparece nos créditos do filme como uma criação de Paurillo Barroso, com coreografias de Yuco Lindberg. Naquele mesmo ano, Paurillo Barroso criou para o Cassino Atlântico, do Rio de Janeiro, um show de carnaval baseado no "balanceio", um ritmo oriundo do Ceará, e com músicas compostas por Lauro Maia e interpretadas pelo conjunto Vocalistas Tropicais.

No filme, a canção é executada pelo mesmo conjunto e com a presença dos dançarinos Carmen Brown, Jimmy Upshaw e Edith de Souza, também presentes no show do cassino, além de alguns figurantes. $\mathrm{O}$ grande interesse desse número talvez seja o registro cinematográfico, ou seja, de maior alcance, de um espetáculo bastante anunciado na imprensa carioca, mas que ficaria restrito apenas aos frequentadores do cassino.

Um momento de grande importância no teatro de revista é a apoteose, "o grande quadro final, cujo objetivo é provocar aplausos e entusiasmos. É sempre musicado e toda a companhia vem cantando diretamente para a plateia" (Veneziano, 2006: 154). Caídos do céu também possui sua apoteose de encerramento. Embora sem a presença de todos os artistas do filme, a cena final é ambientada no céu, com o personagem Felizardo Boaventura e várias girls (apelido dado as dançarinas) vestidas de anjos, ao som da canção "Olinda" (Herivelto Martins e Heitor dos Prazeres), novamente filmado em plano aberto. 


\title{
Considerações finais
}

Em ocasião do lançamento no cinema os críticos dos jornais não hesitaram em depreciar o filme de modo bastante ofensivo. Pedro Lima escreveu que: "sem dúvida, em que pese toda a boa vontade com que se acolhe ao filme nacional, Caídos do céu não deveria ser apresentado em público (Diário da Noite, 2 maio 1946: 6). Por sua vez, Jonald afirma:

\begin{abstract}
Desde que efetuamos crônicas neste jornal, eis a pior realização nacional... Ademar Gonzaga, batalhador incansável, figura de inegável valor - a quem estimamos pessoalmente - devia ter arquivado o filme. Não possui quase nenhuma circunstância destacável ( $A$ Noite, 26 abr 1946: 4).
\end{abstract}

Porém esse tipo de ataque era comum a maioria dos filmes de carnaval, criticados por sua recorrente precariedade e pela frequente pressa nas filmagens, resultando muitas vezes em produtos com uma qualidade técnica ruim. Mas a crítica também desconsiderava esses filmes devido a uma suposta falta de atributos cinematográficos e por sua ligação com outros tipos de entretenimento. Fred Lee, crítico do jornal $O$ Globo diz que "o filme é de carnaval, gênero inventado pelo cinema brasileiro, que se baseia na tolice rasgada" ( $O$ Globo, 26 abr 1946: 5). Jonald compara o filme "com o nível das revistas teatrais de má qualidade" (A Noite, 26 abr 1946: 4). Já Pedro Lima critica os atores teatrais, afirmando que "o único elemento que poderia ser aproveitável é Nelma Costa" (Diário da Noite, 2 maio 1946: 6).

Ao assistirmos esses filmes musicais hoje, o que nos chama a atenção é justamente esse aspecto que, aos olhos dos críticos da época, era um defeito: o uso de diversos elementos de outros meios artísticos, como o teatro de revista, os shows de cassino e o rádio. $\mathrm{O}$ modo como o diretor trabalha com esses elementos de grande apelo popular faz com que o filme traga uma riqueza ao registrar a cultura de uma época, embora provavelmente a intenção ao se produzir um filme como esse não fosse sua sobrevivência ao longo do tempo. 
No entanto parece claro que a estratégia de uma produção como Caídos do céu era atrair público a partir de um acúmulo de atrações, mesmo em sacrifício de uma narrativa bem costurada, como esperavam os críticos, que tinham como referência a linguagem clássica hollywoodiana. Nesse ponto, mais uma vez podemos perceber uma semelhança com o teatro de revista, que tinha como uma característica essencial incorporar todo tipo de atualidade em seus espetáculos, buscando agradar um público exigente, mas sem deixar de lado suas convenções e sua estrutura.

\section{Referências}

Antunes, D. (2002). Fora do sério: um panorama do teatro de revista no Brasil. Rio de Janeiro: Funarte.

Barros, L. (1978). Minhas memórias de cineasta. Rio de Janeiro: Artenova: Embrafilme.

Bernardet, J. C. (1995). Historiografia clássica do cinema brasileiro. São Paulo: Annablume.

Costa, F. M. (2006). O som no cinema brasileiro: revisão de uma importância indeferida. Tese de doutorado, Universidade Federal Fluminense, Niterói, Brasil.

Dicionário Cravo Albin da música popular brasileira. Recuperado de: http://www.dicionariompb.com.br/

Filmografia da Cinemateca Brasileira. Recuperado de: http://www.cinemateca.gov.br/

Freire, R. L. (2011). Carnaval, mistério e gangsters: O filme policial no Brasil (1915-1951). Tese de doutorado, Universidade Federal Fluminense, Niterói, Brasil.

Veneziano, N. (1991). O teatro de revista no Brasil: dramaturgia e convenções. Campinas: Pontes: UNICAMP.

Veneziano, N. (2006). De pernas para o ar: teatro de revista em São Paulo. São Paulo: Imprensa Oficial. 